\title{
Functional land-use change effects on soil fungal communities in Chilean temperate rainforests
}

\author{
César Marín ${ }^{1 *}$, Roberto Godoy ${ }^{1}$, Eduardo Valenzuela $^{2}$, Michael Schloter $^{3}$, Tesfaye Wubet ${ }^{4}$, \\ Jens Boy ${ }^{5}$, Silvia Gschwendtner ${ }^{3}$
}

${ }^{1}$ Instituto de Ciencias Ambientales y Evolutivas, Universidad Austral de Chile, 5090000 ,Valdivia, Chile. ${ }^{2}$ Instituto de Bioquímica y Microbiología, Universidad Austral de Chile, 5090000. Valdivia, Chile. ${ }^{3}$ Helmholtz Zentrum München, Research Unit of Comparative Microbiome Analysis, 85764 Neuherberg, Germany. ${ }^{4}$ Helmholtz Zentrum für Umweltforschung, Department of Soil Ecology, 61120 Halle/Saale, Germany. ${ }^{5}$ Institute of Soil Science, Leibniz Universität Hannover, 30167 Hannover, Germany. *Corresponding author: cesar. marin@postgrado.uach.cl

\begin{abstract}
By reducing soil organic matter and litter input, land-use changes are predicted to decrease total soil fungal diversity, but at functional levels this have been poorly studied. It is expected, though, that increasing disturbance decreases saprotrophic and mycorrhizal fungi biodiversity. This study aimed to determine the effects of land-use changes on the phylogenetic and functional diversity of soil fungi in the Southern Andes. We assessed the fungal communities of Andosol topsoil at $1 \mathrm{~cm}$ and $10 \mathrm{~cm}$ soil depth. The soil samples were obtained from a gradient of anthropogenic disturbance; specifically, plots were located within pristine forest, overstory-managed, and clearcut conditions. We used a cultivation-independent molecular barcoding approach to assess fungal diversity and identify 1,173 OTUs from which 401 were assigned to a functional guild. While we found higher phylogenetic richness in clear-cut conditions, these soils had higher relative abundances of plant pathogen fungi and lower relative abundances of saprotrophic and ectomycorrhizal fungi compared to the other treatments. The opposite pattern was found in pristine forest. Thus, fungal species richness itself does not seem to reflect ecosystem health. Interestingly though, the lower phylogenetic diversity found in pristine forest was compensated by a higher diversity of fungi involved in nutrient cycling.
\end{abstract}

Keywords: Ectomycorrhizal fungi, functional biodiversity, land-use change, Nothofagus forest, plant pathogenic fungi, saprotrophic fungi 


\section{Introduction}

Soil fungal communities are crucial for ecosystem functioning and strongly drive abiotic soil conditions (van der Heijden et al., 2008; Aguilera et al., 2017; Cornejo et al., 2017). Vice versa, fungal assemblages are dependent on soil physicochemical conditions, plant nutritional status, and plant community composition (Lauber et al., 2008). Globally, pH, P, and Ca are the main edaphic factors structuring soil fungal communities (Tedersoo et al., 2014).

The removal of forest vegetation by severe anthropogenic intervention because of land-use change has led to drastic changes in plant biomass and litter inputs and has severely affected the composition, biodiversity, productivity, and functionality of soil microbiota (Oyarzún et al., 2007; Holden and Treseder, 2014; Mueller et al., 2016). Specifically, the removal of vegetation (trees and/or understory removal, clearcutting, logging) from natural ecosystems has been shown to drastically affect total soil fungal richness (Bååth et al., 1995; Spurgeon et al., 2013; Tedersoo et al., 2014; Mueller et al., 2016), although contradicting results have also been reported (Spurgeon et al., 2013). Mueller et al. (2016) have shown that clearcutting favors generalist fungi in tropical ecosystems while Hagerman et al. (1999) found no effects of clear-cutting on alpine ectomycorrhizal (EM) fungi. Additionally, Zhao et al. (2011) have shown that a complete removal of vegetation significantly decreases saprotrophic fungi diversity in southern China, but a partial removal (understory plants) has no effect. These contrasting results reveal that the interactions between ecosystem type, degree of vegetation removal, and fungal guild are complex.

In Southern Chile, various naturally and anthropogenically induced disturbances are responsible for temporal and permanent land-use changes that significantly impact local ecosystems (Godoy et al., 2009; Kitzberger et al., 2016; Marín et al., 2016; Bueno et al., 2017). Thus, the effects of disturbance can be expected to be highly severe even on highly pristine ecosystems. Overall, as Chilean temperate rainforests are considered to have preindustrial biogeochemical conditions (Oyarzún et al., 2007; Godoy et al., 2009), they are an ideal model system to investigate the impacts of anthropogenic induced land-use changes on soil microbial communities. While no research has been done to document the effects of land-use change on Southern Chilean soil fungal assemblages, studies conducted in other systems can help stimulate some hypotheses. Firstly, in most ecosystems, soil fungal richness decreases with increasing removal of vegetation (Holden and Treseder, 2014; Spurgeon et al., 2013), and the diversity of aboveground and belowground biomass has been shown to be positively correlated (Tedersoo et al., 2014). Secondly, the diversity of EM and saprotrophic fungi would decrease drastically with increasing removal of Nothofagus spp. because EM fungi are limited to Nothofagus spp. in southern Chilean forests (Godoy et al., 1994), and in these forests, the decomposition of leaf litter is fundamental to nutrient cycling (Oyarzún et al., 2007; Godoy et al., 2009). By altering the soil microbial community, anthropogenic disturbances such as deforestation cause the production and decomposition of soil organic matter to decrease. After the immediate effects of deforestation have taken place, soil functional activities such as mycorrhizal symbiosis and decomposition are substantially reduced due to the decomposition of the remaining dead biomass. In contrast, most soil nutrients are fully utilized in pristine forests. Thus, we expected to find a lower functional diversity of fungal guilds related to nutrient cycling in areas with a high level of anthropogenic disturbance. Conversely, we expected that pristine ecosystems would house a 
higher proportion of nutrient-cycling related fungi. These assumptions beg the question: does the soil fungal community have mechanisms for functional compensation in response to disturbance?

Specifically, does a higher proportion of nutrient-cycling related fungi compensate for low overall diversity (species richness)? Derived from the concept of 'nestedness' (James et al., 2012), which predicts that during ecological succession more specialized species perform increasingly specified functions, disturbance could cause functional, structural and interaction changes to occur in communities yet classical species richness might not be affected. Thus, with the basis of generalist species, specialists are required towards the succession. Generally, both types of species (generalists and specialists) are closely related (James et al., 2012). Thus, as increasing disturbance reflects an inverse ecological succession (clear-cut could be seen as a starting point of an intact ecosystem), it is expected that there are more nutrient-cycling related specialist soil fungi in less intervened forests. Conversely, pristine forests, as they possess more competed resources (soil, litter, host plants, etc.), are expected to be more nested, i.e. to have more nutrient-cycling related specialist fungi. Meanwhile, in clear-cut areas, abundant and non-competed resources are expected to generate less nested communities, i.e. to have less nutrient-cycling related specialist fungi. These ecological expectations (James et al., 2012) coincide with the biogeochemical observations (Oyarzún et al., 2007; Godoy et al., 2009; Kitzberger et al., 2016) mentioned above. Here we analyzed the effects of land-use change on the phylogenetic and functional diversity of soil fungi in a temperate rainforest in Southern Chile. Specifically, we sampled two different soil depths $(1 \mathrm{~cm}$ and $10 \mathrm{~cm})$ in pristine, overstory managed, and clear-cut forests. Furthermore, the edaphic factors structuring the soil fungal assemblages were identified in the six treatments (three land-uses * two depths). Lastly, molecular barcoding approaches were used to overcome the bias introduced by cultivation of fungal communities.

\section{Materials and Methods}

\subsection{Study sites and experimental design}

The study sites were in Puyehue National Park, Southern Chile $\left(40^{\circ} 79^{\prime} \mathrm{S}-72^{\circ} 95^{\prime} \mathrm{W}\right.$; between 850 860 m.a.s.1.). We selected three $30 \mathrm{~m}$ x $30 \mathrm{~m}\left(900 \mathrm{~m}^{2}\right)$ experimental plots of Nothofagus betuloides (Mirb.) Oerst forest that represented the following treatments: Cleared $=$ total removal of vegetation (overstory and understory removed in 1999), Managed= partial removal of vegetation ( $N$. betuloides and overstory removed in 1999), leaving only understory plants, and Pristine $=$ pristine forest (old-growth forest). There was no damaged or ill vegetation in any plot. The plots were separated by $500 \mathrm{~m}$ and had equal exposure, soil type, and altitude.

The characteristics of the vegetation were assessed in the Pristine plot. In general, old-growth Nothofagus forests are characterized by the frequent presence of large broad-leafed emergent canopy trees together with patchy regeneration, and they have been shown to persist for $>325$ years (Oyarzún et al., 2004). Specifically, in our plots, the forest community presented a mean tree height of $45 \mathrm{~m}$, tree density of 299 tree $\mathrm{ha}^{-1}$, and basal area of $111.97 \mathrm{~m}^{2} \mathrm{ha}^{-1}$. The tree canopy cover was $70 \%$. The overstory ( $<25 \mathrm{~m}$ height and $20 \%$ cover) consisted of $N$. betuloides, Saxegothaea cosnpicua Lindl, Weinmannia trichosperma CAV, and Drimys winteri J.R. et G. Forster. The understory $(<10 \mathrm{~m}$ height) was dominated by S. conspicua Lindl and Myrceugenia planipes (H. et A.) Berg (50\% cover). In the lower stratum $(<2 \mathrm{~m}, 10 \%$ of cover), the main species were Chusquea montana Phil., Blechnum magellanicum (A.N. Desv.) Mett, Myrcengenia planipes, Azara lanceolata Hook f., Luma apiculata (D.C) Burret. and 
Desfontainea spinosa $\mathrm{R}$. et P. The forests studied are characterized by high structural complexity and plant functional diversity. Annual precipitation in the area is $>7,000 \mathrm{~mm}$, of which $90 \%$ is rainfall and $10 \%$ is snowfall; the annual mean temperature is $4{ }^{\circ} \mathrm{C}$ (Oyarzún et al., 2004). These forests are mainly situated on geological substratum of volcanic origin; thus, the soils are formed from deposits of volcanic ash (Matus, 2003). At the time of sampling the soils were still in an active stage of carbon accumulation and nitrogen retention (Garrido and Matus, 2012).

Three random sample spots were selected in each plot. Sampling took place in summer 2013. From each spot, $500 \mathrm{~g}$ of soil were taken from $1 \mathrm{~cm}$ and $10 \mathrm{~cm}$ soil depths after removing the $\mathrm{O}$ horizon. These two depths were selected due to the strong gradient in fungal diversity with soil depth observed in other studies in the region (Valenzuela et al., 2001). Thus, this study involved six combinations of treatments (three land-uses * two depths) resulting in 18 soil samples. Soil samples were stored on dry ice and transported to the laboratory within $24 \mathrm{~h}$. After homogenizing, a subsample of $2 \mathrm{~g}$ of each soil sample was used for DNA extraction. The remainder of the soil samples were dried at ambient-temperature, sieved to $2 \mathrm{~mm}$, and used for soil chemical analysis.

\subsection{Soil chemical analysis}

Three subsamples of each of the 18 soil samples were used to measure soil physicochemical parameters (54 subsamples overall). Distilled water was used for both $\mathrm{pH}$ and electrical conductivity (EC) measurements. Total carbon (C) was determined using sodium dichromate and sulfuric acid oxidation, and total nitrogen $(\mathrm{N})$ was measured by Kjeldahl digestion (Zagal and Sadzawka, 2007). Organic matter (OM) was determined according to Walkley and Black (1934). Plant available phosphorous (P_a) was determined using Olsen extractions (Zagal and Sadzawka, 2007). $\mathrm{Ca}, \mathrm{K}, \mathrm{Mg}$, and $\mathrm{Na}$ were extracted using $1 \mathrm{M}$ $\mathrm{NH}_{4} \mathrm{OAc}(\mathrm{pH} 7.0)$, and an atomic absorption spectrophotometer was used for measurements (AAnalyst 400, PerkinElmerInc, Massachusetts, USA; Zagal and Sadzawka, 2007).

\subsection{DNA extraction, PCR, and 454 pyro-sequencing}

DNA was extracted from $0.3 \mathrm{~g}$ soil via phenolchloroform-based extraction described by Töwe et al. (2011), using a Precellys24 Instrument (PeqLab, Erlangen, Germany). Quality and quantity of the nucleic acids were checked using a spectrophotometer (Nanodrop, PeqLab, Erlangen, Germany) and gel electrophoresis. DNA extracts were stored at $-20{ }^{\circ} \mathrm{C}$ until further processing.

The universal fungal primers ITS1F (5'- CTT GGT CAT TTA GAG GAA GTA A-3'; Gardes and Bruns, 1996) and ITS4 (5'- TCC TCC GCT TAT TGA TAT GC-3'; White et al., 1990) were extended with unique Multiplex Identifiers (MID), a four-base library key, and the respective adapters for sample identification. The sequence reaction PCR was performed in technical triplicates for each sample using a T3 thermocycler (Biometra GmbH, Göttingen, Germany). The following conditions were used: initial denaturation $\left(95^{\circ} \mathrm{C}\right.$, 5 min), followed by 25 cycles of denaturation $\left(94^{\circ} \mathrm{C}\right.$, $60 \mathrm{~s})$, annealing $\left(50{ }^{\circ} \mathrm{C}, 60 \mathrm{~s}\right)$ and elongation $\left(72^{\circ} \mathrm{C}\right.$, $90 \mathrm{~s})$, ending with a final extension $\left(72{ }^{\circ} \mathrm{C}, 10 \mathrm{~min}\right)$. Each $25 \mu$ PCR reaction contained $1 \times$ PCR buffer with $1.8 \mathrm{mM} \mathrm{MgCl} 2,0.2 \mathrm{mM}$ dNTPs, $1.25 \mathrm{U}$ HighFidelity polymerase (Roche, Penzberg, Germany), $0.2 \mu \mathrm{M}$ of each primer, $0.5 \mu 13 \% \mathrm{BSA}$ and $20 \mathrm{ng}$ of template DNA. The technical triplicates were pooled and all samples were purified using the Gel and PCR Cleanup Kit (Macherey Nagel, Düren, Germany). The amount of products was quantified using the Quant-iT Pico Green dsDNA Assay Kit (Invitrogen, Karlsruhe, 
Germany). Afterwards, fragment size and concentration was measured using a Bioanalyzer 2100 with a DNA 7500 chip (Agilent, Böblingen, Germany). PCR specificity was confirmed using three PCR controls that did not contain template DNA (DNA concentration not measurable, no signal on Bioanalyzer). Subsequently, the samples were pooled in equimolar ratios of 1,010 molecules $\mu 1^{-1}$, and emulsion PCR was performed with the following conditions: $94{ }^{\circ} \mathrm{C}$ for 4 min, followed by 50 cycles of $94{ }^{\circ} \mathrm{C}$ for $30 \mathrm{~s}$, and 60 ${ }^{\circ} \mathrm{C}$ for 10 min each. Amplicon pyrosequencing was performed on a 454 GS FLX Titanium system (Roche, Penzberg, Germany).

\subsection{Bioinformatic analysis}

To reduce sequencing errors, multiple levels of sequence processing and quality filtering were performed as described in Wubet et al. (2012). Flowgrams were extracted according to $100 \%$ barcode similarity; reads with an average quality score of $<$ 25 , read length of $<200 \mathrm{bp}$, and ambiguous bases and homopolymers of $>8$ bases were removed and barcodes and primers were trimmed using the split libraries script available in the "Quantitative Insights In Microbial Ecology pipeline" -QIIME (Caporaso et al., 2010). Using MOTHUR, reads were trimmed to a maximum read length of $450 \mathrm{bp}$ (Schloss et al., 2009).

Afterwards, sequences were clustered and assigned to Operational Taxonomic Units (OTUs) via the QIIME implementation of CDHIT with a threshold of $97 \%$ pairwise identity. The most abundant representative sequences were selected and assigned to the respective taxa according to NCBI taxonomy. The phylogenetic assignment was based on BlastN searching using the NCBI nucleotide database for fungi annotation, excluding uncultured and environmental sequences. The blast based taxonomic assignment script of the software for Cleaning and Analyzing Next Generation
Sequences -CANGS (Pandey et al. 2010) was used for further processing. Chimeras were removed via the chimera uchime algorithm in MOTHUR using the same dataset as reference. For further sequence data analysis, rarefaction curves, OTU richness and diversity indices were calculated using OTUs clustered at 97\% similarity. Phylogenetic analysis was also done based on $97 \%$ similarity.

The nucleotide sequence data obtained in this study was deposited to the NCBI Sequence Read Archive under the SRA accession number SRP097883 and Bioproject Number PRJNA368954.

\subsection{Statistical analysis}

To analyze fungal diversity patterns, three different matrices were compiled: some analyses were conducted using the raw matrix (18 samples X No. OTUs), others were conducted using the treatment combination (i.e. Pristine_10 cm) matrix (6 combinations X No. OTUs; joined and averaged raw matrix), and for visualization purposes, some analyses (such as diversity indices) utilized averages from the raw matrix by treatment combination. Below, we have clearly indicated when these matrices were used.

An OTU accumulation curve across the 18 samples was calculated using the function accumresult of the BiodiversityR package (Kindt and Coe, 2005) in R 3.2.5 (R Development Core Team, 2016). To describe diversity patterns in the six treatments, several diversity indices (Richness, S; Shannon, $\mathrm{H}^{\prime}$; Simpson, 1-D ; $_{1}$ Inverse Simpson, D2; Evenness, J'; Berger, BP) were calculated using the function diversityresult of the BiodiversityR R package (Kindt and Coe, 2005). To calculate the alpha, beta, and gamma diversity contribution to the Simpson index $\left(1-\mathrm{D}_{1}\right)$, the function contribdiv of the R package vegan (Oksanen et al., 2015) was used. 
Genus level information for fungal functional guilds was obtained using the database on Tedersoo et al. (2014). Functional guilds were always assigned at the genus or species level, except for the Subphylum Glomeromycotina OTUs, which were functionally assigned as arbuscular mycorrhizal (AM) fungi. For each plot, after the functional assignment was made, the number of reads assigned to each guild was standardized by rarefaction to 1,333 reads, which was the lowest number of functionally assigned reads for any given sample (belonged to sample two of the Pristine_1 cm combination).

Rényi diversity profiles were calculated for each treatment using the function renyiresult of the BiodiversityR R package (Kindt and Coe, 2005); this was done for total soil fungi, saprotrophs, EM fungi, and plant pathogen fungi. Rényi diversity profile values (H-alpha) were calculated based on the relative abundance of each species and using a scale parameter (alpha) that ranged from zero to infinity (Kindt and Coe, 2005). Rényi profiles are directly related to richness $(\mathrm{S})$, and to the Shannon $\left(\mathrm{H}^{\prime}\right)$, Simpson $\left(\mathrm{D}_{1}\right)$ and Berger (BP) indices. Thus, in a Rényi profile, the Halpha values reflect alpha diversity (i.e., community $\mathrm{A}$ is more diverse and more evenly distributed than community B if its $\mathrm{H}$-alpha is continuously higher compared to the $\mathrm{H}$-alpha of community B; Kindt and Coe, 2005). To test the effect of land-use (Cleared, Managed or Pristine) and soil depth (1 cm and 10 $\mathrm{cm}$ ) on saprotroph, EM and plant pathogen fungal richness (number of OTUs per sample) and proportional abundance, simple linear models ( land-use * depth) were used.

Canonical Correspondence Analysis (CCA) that incorporated 10 soil chemistry variables was conducted using the function $c c a$ of the $\mathrm{R}$ package vegan (Oksanen et al., 2015) to test which edaphic variables determined the community composition of total soil fungi, saprotroph, ectomycorrhizal (EM) and plant pathogen fungal communities. Final variables were selected by backward model selection using the ordistep function on the R package vegan (Oksanen et al., 2015).

\section{Results}

\subsection{Soil chemical analysis}

The dark Andosols of these plots are constantly formed by ash deposition from volcanic events (there have been at least three in the last five years). Soil chemical and physical characteristics are shown in Table 1. For all three land-use scenarios tested, the soil samples from $10 \mathrm{~cm}$ depth were more acidic and had a higher electrical conductivity and nutrient content compared to soil samples obtained from 1 $\mathrm{cm}$ depth. Interestingly, these depth-related differences were less pronounced in the Pristine plot samples and more pronounced in the Cleared plot samples. Consequently, the nutrient content of the soil samples obtained from the Cleared plot was mostly higher compared to that of soils from the same depth from the other two plots. Conversely, the highest nutrient levels were observed in the $1 \mathrm{~cm}$ depth Pristine plot samples.

\subsection{Structural diversity of fungal communities}

In total, 212,857 raw fungal sequence reads were generated from the 454-pyrosequenced PCR amplicons. After noise filtering, chimera checks, and removal of erroneous reads, 85,194 high quality ITS rDNA sequences with a length of 200-450 bp remained; at $97 \%$ similarity levels it was possible to assign these sequences to 1,173 OTUs. To compare samples without statistical bias, subsampling of 4,570 reads was performed to reflect the lowest read number obtained per sample. An analysis of the 
rarefaction curves indicated that $97-99 \%$ of the total diversity was covered; thus, the sampling depth was adequate as showed by further analyses at
OTU97 levels (results not shown here). 18 soil samples sufficiently covered soil fungal richness (Figure 1).

Table 1. Soil chemical characteristics of the 18 study samples

\begin{tabular}{|c|c|c|c|c|c|c|c|c|c|c|}
\hline Sample & $\mathrm{pH}$ & $\mathrm{EC}(\mathrm{uS} / \mathrm{cm})$ & $\mathrm{C}(\%)$ & $\mathrm{N}(\%)$ & OM (\%) & $\begin{array}{l}\text { P_a } \\
(\overline{m g} / \mathrm{Kg})\end{array}$ & $\mathrm{Ca}(\mathrm{mg} / \mathrm{Kg})$ & $\mathrm{K}(\mathrm{mg} / \mathrm{Kg})$ & $\begin{array}{l}\mathrm{Mg} \\
(\mathrm{mg} / \mathrm{Kg})\end{array}$ & $\begin{array}{l}\mathrm{Na} \\
(\mathrm{mg} / \mathrm{Kg})\end{array}$ \\
\hline Cleared_1cm.1 & $5.7 \pm 0.07 \mathrm{c}$ & $49 \pm 0.97 b$ & $1.1 \pm 0.03 \mathrm{a}$ & $0.05 \pm 0.01 \mathrm{a}$ & $2.0 \pm 0.12 \mathrm{a}$ & $3.0 \pm 0.12 \mathrm{a}$ & $41 \pm 1.43 \mathrm{a}$ & $15 \pm 1.08 \mathrm{a}$ & $4 \pm 0.27 \mathrm{a}$ & $6 \pm 0.54 \mathrm{a}$ \\
\hline Cleared_1 $1 \mathrm{~cm} .2$ & $5.8 \pm 0.07 \mathrm{~d}$ & $52 \pm 0.98 \mathrm{~b}$ & $1.1 \pm 0.03 \mathrm{a}$ & $0.03 \pm 0.01 \mathrm{a}$ & $2.4 \pm 0.12 b$ & $2.6 \pm 0.12 \mathrm{a}$ & $47 \pm 1.44 \mathrm{~b}$ & $11 \pm 1.09 \mathrm{a}$ & $4 \pm 0.27 \mathrm{a}$ & $8 \pm 0.54 b$ \\
\hline Cleared_1cm.3 & $5.5 \pm 0.07 \mathrm{~b}$ & $48 \pm 0.96 b$ & $1.0 \pm 0.03 \mathrm{a}$ & $0.05 \pm 0.01 \mathrm{a}$ & $1.9 \pm 0.12 \mathrm{a}$ & $3.1 \pm 0.12 b$ & $43 \pm 1.41 \mathrm{a}$ & $15 \pm 1.07 \mathrm{a}$ & $3 \pm 0.27 \mathrm{a}$ & $8 \pm 0.53 b$ \\
\hline Cleared_10cm.1 & $4.4 \pm 0.08 \mathrm{a}$ & $190 \pm 1.06 \mathrm{~d}$ & $12.6 \pm 0.03 \mathrm{~d}$ & $0.67 \pm 0.01 \mathrm{~d}$ & $22.0 \pm 0.13 \mathrm{~d}$ & $12.6 \pm 0.13 b$ & $761 \pm 1.55 \mathrm{~d}$ & $249 \pm 1.17 \mathrm{~d}$ & $132 \pm 0.29 \mathrm{~d}$ & $34 \pm 0.59 \mathrm{~d}$ \\
\hline Cleared_10cm.2 & $4.2 \pm 0.08 \mathrm{a}$ & $188 \pm 1.07 \mathrm{~d}$ & $12.0 \pm 0.03 \mathrm{~d}$ & $0.59 \pm 0.01 \mathrm{c}$ & $25.0 \pm 0.14 \mathrm{~d}$ & $13.1 \pm 0.14 \mathrm{c}$ & $798 \pm 1.57 \mathrm{~d}$ & $234 \pm 1.19 \mathrm{~d}$ & $119 \pm 0.30 \mathrm{~d}$ & $38 \pm 0.59 \mathrm{~d}$ \\
\hline Cleared_10cm.3 & $4.1 \pm 0.08 \mathrm{a}$ & $189 \pm 1.08 \mathrm{~d}$ & $11.8 \pm 0.03 \mathrm{c}$ & $0.69 \pm 0.01 \mathrm{~d}$ & $19.0 \pm 0.14 c$ & $12.0 \pm 0.14 \mathrm{~b}$ & $734 \pm 1.58 \mathrm{~d}$ & $261 \pm 1.20 \mathrm{~d}$ & $137 \pm 0.30 \mathrm{~d}$ & $32 \pm 0.60 \mathrm{~d}$ \\
\hline Managed_1cm.1 & $6.0 \pm 0.10 \mathrm{~d}$ & $38 \pm 1.41 \mathrm{a}$ & $0.7 \pm 0.04 \mathrm{a}$ & $0.04 \pm 0.01 \mathrm{a}$ & $1.0 \pm 0.18 \mathrm{a}$ & $2.8 \pm 0.18 \mathrm{a}$ & $19 \pm 2.07 \mathrm{a}$ & $15 \pm 1.56 \mathrm{a}$ & $4 \pm 0.39 \mathrm{a}$ & $2 \pm 0.78 \mathrm{a}$ \\
\hline Managed_1 $1 \mathrm{~cm} .2$ & $5.8 \pm 0.09 \mathrm{~d}$ & $39 \pm 1.28 \mathrm{a}$ & $0.7 \pm 0.04 \mathrm{a}$ & $0.03 \pm 0.01 \mathrm{a}$ & $1.0 \pm 0.16 \mathrm{a}$ & $2.8 \pm 0.16 \mathrm{a}$ & $17 \pm 1.88 \mathrm{a}$ & $12 \pm 1.42 \mathrm{a}$ & $4 \pm 0.36 \mathrm{a}$ & $2 \pm 0.71 \mathrm{a}$ \\
\hline Managed_1cm.3 & $6.1 \pm 0.09 \mathrm{~d}$ & $37 \pm 1.16 \mathrm{a}$ & $0.5 \pm 0.03 \mathrm{a}$ & $0.08 \pm 0.01 \mathrm{~b}$ & $1.3 \pm 0.15 \mathrm{a}$ & $2.2 \pm 0.15 \mathrm{a}$ & $17 \pm 1.71 \mathrm{a}$ & $20 \pm 1.29 b$ & $5 \pm 0.32 b$ & $3 \pm 0.65 \mathrm{a}$ \\
\hline Managed_10cm.1 & $4.8 \pm 0.13 \mathrm{a}$ & $137 \pm 1.70 \mathrm{~d}$ & $14.3 \pm 0.05 \mathrm{~d}$ & $0.68 \pm 0.01 \mathrm{~d}$ & $25.0 \pm 0.22 \mathrm{~d}$ & $14.0 \pm 0.22 \mathrm{c}$ & $554 \pm 2.50 \mathrm{~d}$ & $158 \pm 1.89 \mathrm{~d}$ & $89 \pm 0.47 \mathrm{~d}$ & $21 \pm 0.95 \mathrm{c}$ \\
\hline Managed_10 $\mathrm{cm} .2$ & $4.3 \pm 0.11 \mathrm{a}$ & $124 \pm 1.55 \mathrm{c}$ & $14.1 \pm 0.04 \mathrm{~d}$ & $0.54 \pm 0.01 \mathrm{c}$ & $28.0 \pm 0.20 \mathrm{~d}$ & $12.0 \pm 0.20 \mathrm{~b}$ & $538 \pm 2.27 \mathrm{c}$ & $154 \pm 1.72 \mathrm{~d}$ & $83 \pm 0.43 d$ & $24 \pm 0.86 \mathrm{~d}$ \\
\hline Managed_10cm.3 & $4.5 \pm 0.14 \mathrm{a}$ & $145 \pm 1.87 \mathrm{~d}$ & $18.0 \pm 0.05 \mathrm{~d}$ & $0.59 \pm 0.01 \mathrm{c}$ & $22.0 \pm 0.24 \mathrm{~d}$ & $13.0 \pm 0.24 \mathrm{c}$ & $542 \pm 2.75 \mathrm{~d}$ & $142 \pm 2.08 \mathrm{c}$ & $77 \pm 0.52 \mathrm{c}$ & $29 \pm 1.04 \mathrm{~d}$ \\
\hline Pristine_1 $1 \mathrm{~cm} .1$ & $5.5 \pm 0.15 b$ & $38 \pm 2.06 a$ & $2.3 \pm 0.06 \mathrm{~b}$ & $0.12 \pm 0.01 \mathrm{~b}$ & $4.0 \pm 0.26 \mathrm{~b}$ & $14.6 \pm 0.26 \mathrm{~d}$ & $111 \pm 3.03 \mathrm{~b}$ & $18 \pm 2.29 b$ & $13 \pm 0.57 b$ & $6 \pm 1.14 \mathrm{a}$ \\
\hline Pristine_ $1 \mathrm{~cm} .2$ & $5.6 \pm 0.17 \mathrm{c}$ & $39 \pm 2.27 \mathrm{a}$ & $2.1 \pm 0.06 \mathrm{~b}$ & $0.09 \pm 0.01 \mathrm{~b}$ & $4.0 \pm 0.29 b$ & $12.8 \pm 0.29 \mathrm{c}$ & $103 \pm 3.33 b$ & $18 \pm 2.52 b$ & $12 \pm 0.63 b$ & $5 \pm 1.26 \mathrm{a}$ \\
\hline Pristine_1 $1 \mathrm{~cm} .3$ & $5.7 \pm 0.18 \mathrm{c}$ & $44 \pm 2.49 \mathrm{~b}$ & $1.9 \pm 0.07 \mathrm{~b}$ & $0.16 \pm 0.01 \mathrm{~b}$ & $5.0 \pm 0.32 b$ & $17.0 \pm 0.32 \mathrm{~d}$ & $123 \pm 3.66 \mathrm{~b}$ & $14 \pm 2.77 \mathrm{a}$ & $12 \pm 0.69 \mathrm{~b}$ & $6 \pm 1.38 \mathrm{a}$ \\
\hline Pristine_10cm.1 & $5.2 \pm 0.24 b$ & $123 \pm 3.32 \mathrm{c}$ & $9.7 \pm 0.09 \mathrm{c}$ & $0.57 \pm 0.02 \mathrm{c}$ & $17.0 \pm 0.42 \mathrm{c}$ & $28.8 \pm 0.42 \mathrm{~d}$ & $237 \pm 4.87 \mathrm{c}$ & $50 \pm 3.68 \mathrm{c}$ & $28 \pm 0.92 \mathrm{c}$ & $20 \pm 1.84 \mathrm{c}$ \\
\hline Pristine_ $10 \mathrm{~cm} .2$ & $5.1 \pm 0.22 b$ & $128 \pm 3.52 \mathrm{c}$ & $9.1 \pm 0.08 \mathrm{c}$ & $0.66 \pm 0.02 \mathrm{~d}$ & $19.0 \pm 0.48 \mathrm{c}$ & $22.3 \pm 0.38 \mathrm{~d}$ & $252 \pm 4.43 \mathrm{c}$ & $45 \pm 3.35 \mathrm{c}$ & $25 \pm 0.84 c$ & $22 \pm 1.67 \mathrm{c}$ \\
\hline Pristine_10cm.3 & $5.5 \pm 0.20 \mathrm{~b}$ & $111 \pm 2.74 \mathrm{c}$ & $8.9 \pm 0.08 \mathrm{c}$ & $0.65 \pm 0.02 \mathrm{~d}$ & $19.0 \pm 0.35 \mathrm{c}$ & $24.0 \pm 0.35 \mathrm{~d}$ & $233 \pm 4.23 \mathrm{c}$ & $59 \pm 3.04 \mathrm{c}$ & $24 \pm 0.76 \mathrm{c}$ & $17 \pm 1.82 \mathrm{c}$ \\
\hline
\end{tabular}

Three subsamples were measured for each soil sample. SE indicated by \pm . Letters indicate quartiles

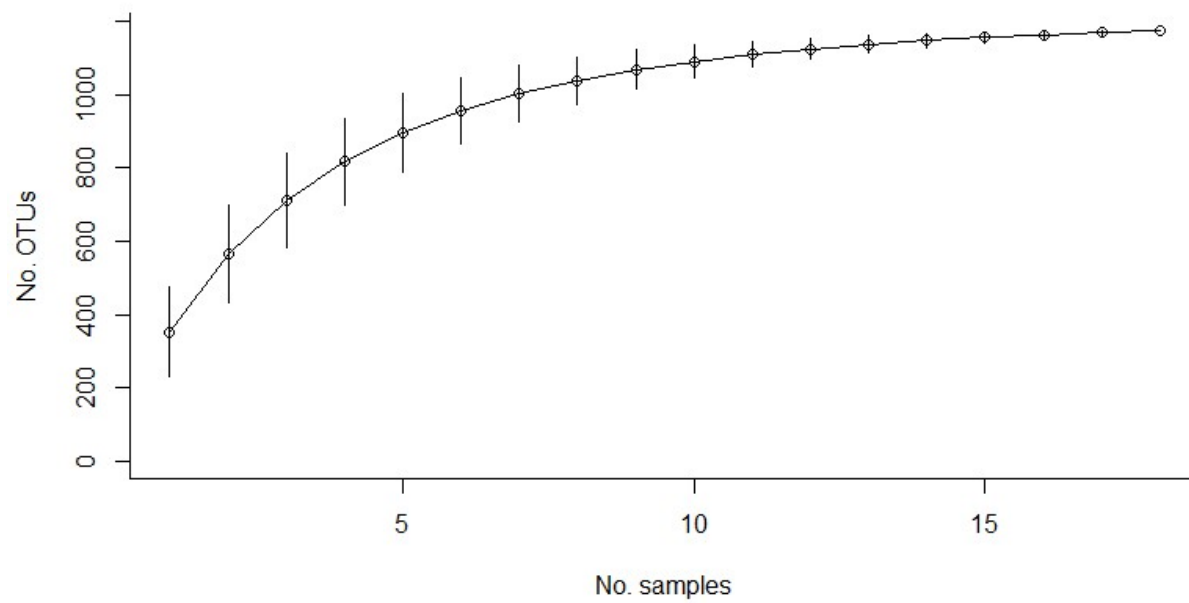

Figure 1. Exact accumulation curve for number of soil samples; 1000 permutations (bars). 
Overall, fungal richness ranged from 222 to 451 OTUs with an average of 352 OTUs per sample. Replicates showed comparable OTU numbers. Strong effects of land-use, depth, and their interaction on total soil fungal richness were found (Table 2). Overall, soil fungal richness was ranked as follows: Cleared_10 $\mathrm{cm}(419$ OTUs) $>$ Managed_1cm $(389$ OTUs $)>$ Cleared_1cm (382 OTUs) $>$ Pristine_1 cm (372 OTUs) $>$ Managed_10 cm (294 OTUs) $>$ Pristine_10 cm $(254$ OTUs) (Table 2, Figure 2).

Table 2. Upper part: Diversity indices by combination (averaged per combination). Lower part: Linear models ( $\sim$ Vegetation*Depth) predicting the respective diversity index.

\begin{tabular}{|c|c|c|c|c|c|c|c|c|c|}
\hline Treatment & Richness (S) & Shannon $\left(\mathrm{H}^{\prime}\right)$ & Simpson (1- & Inverse Simpson & Evenness $\left(\mathrm{J}^{\prime}\right)$ & Berger (BP) & Contribution & 1-D1 & \\
\hline All samples & $429.000 \pm 60.810$ & $4.364 \pm 0.467$ & $0.971 \pm 0.032$ & $34.012 \pm 20.820$ & $0.720 \pm 0.059$ & $0.108 \pm 0.075$ & Alpha & Beta & Gamma \\
\hline Cleared_1cm & $382.000 \pm 12.247$ & $4.847 \pm 0.081$ & $0.984 \pm 0.001$ & $63.074 \pm 5.343$ & $0.815 \pm 0.009$ & $0.057 \pm 0.006$ & $0.984 \pm 0.001$ & $0.010 \pm 0.001$ & $0.994 \pm 0.001$ \\
\hline Cleared_10cm & $418.667 \pm 24.418$ & $4.948 \pm 0.163$ & $0.984 \pm 0.004$ & $67.573 \pm 19.692$ & $0.820 \pm 0.024$ & $0.061 \pm 0.021$ & $0.984 \pm 0.004$ & $0.010 \pm 0.004$ & $0.994 \pm 0.001$ \\
\hline Managed_1cm & $388.667 \pm 20.758$ & $4.655 \pm 0.036$ & $0.978 \pm 0.001$ & $45.557 \pm 2.628$ & $0.781 \pm 0.006$ & $0.081 \pm 0.018$ & $0.978 \pm 0.001$ & $0.014 \pm 0.002$ & $0.992 \pm 0.001$ \\
\hline Managed_10 $\mathrm{cm}$ & $294.333 \pm 4.497$ & $4.151 \pm 0.136$ & $0.963 \pm 0.011$ & $29.245 \pm 7.173$ & $0.730 \pm 0.023$ & $0.117 \pm 0.047$ & $0.963 \pm 0.011$ & $0.028 \pm 0.010$ & $0.991 \pm 0.001$ \\
\hline Pristine_ $1 \mathrm{~cm}$ & $371.667 \pm 22.544$ & $4.559 \pm 0.242$ & $0.974 \pm 0.009$ & $44.563 \pm 15.981$ & $0.770 \pm 0.033$ & $0.081 \pm 0.027$ & $0.974 \pm 0.009$ & $0.017 \pm 0.009$ & $0.992 \pm 0.001$ \\
\hline Pristine_ $10 \mathrm{~cm}$ & $254.333 \pm 23.300$ & $3.755 \pm 0.415$ & $0.920 \pm 0.054$ & $18.236 \pm 8.366$ & $0.678 \pm 0.064$ & $0.217 \pm 0.112$ & $0.920 \pm 0.054$ & $0.069 \pm 0.052$ & $0.990 \pm 0.002$ \\
\hline Vegetation & $21.172 * * *$ & $12.018^{* *}$ & $2.621^{\text {ns }}$ & $9.832 * *$ & $8.432 * *$ & $2.962^{\text {ns }}$ & $2.621^{\mathrm{ns}}$ & $2.447^{\mathrm{ns}}$ & $5.563^{*}$ \\
\hline Depth & $27.241^{* * * *}$ & $10.276^{* *}$ & $3.037^{\text {ns }}$ & $3.636^{\text {ns }}$ & $6.000^{*}$ & $3.865^{\mathrm{ns}}$ & $3.037^{\mathrm{ns}}$ & $3.011^{\text {ns }}$ & $2.238^{\text {ns }}$ \\
\hline Vegetation:Depth & $\begin{array}{l}18.415^{* * *} \\
\mathrm{r}^{2}=0.899\end{array}$ & $\begin{array}{l}4.497^{*} \\
r^{2}=0.783\end{array}$ & $\begin{array}{l}1.486^{\text {ns }} \\
r^{2}=0.484\end{array}$ & $\begin{array}{l}1.854^{\text {ns }} \\
r^{2}=0.692\end{array}$ & $\begin{array}{l}2.218^{\text {ns }} \\
r^{2}=0.695\end{array}$ & $\begin{array}{l}1.751^{\text {ns }} \\
r^{2}=0.525\end{array}$ & $\begin{array}{l}1.486^{\text {ns }} \\
r^{2}=0.484\end{array}$ & $\begin{array}{l}1.528^{\text {ns }} \\
r^{2}=0.477\end{array}$ & $\begin{array}{l}0.444^{\mathrm{ns}} \\
\mathrm{r}^{2}=0.543\end{array}$ \\
\hline
\end{tabular}

Upper part: Richness is the number of OTUs per plot. SE indicated by \pm . Lower part: $\mathrm{F}^{p}, \mathrm{p}: *<0.05, * *<0.01, * * *<0.001$, ns=non-significant

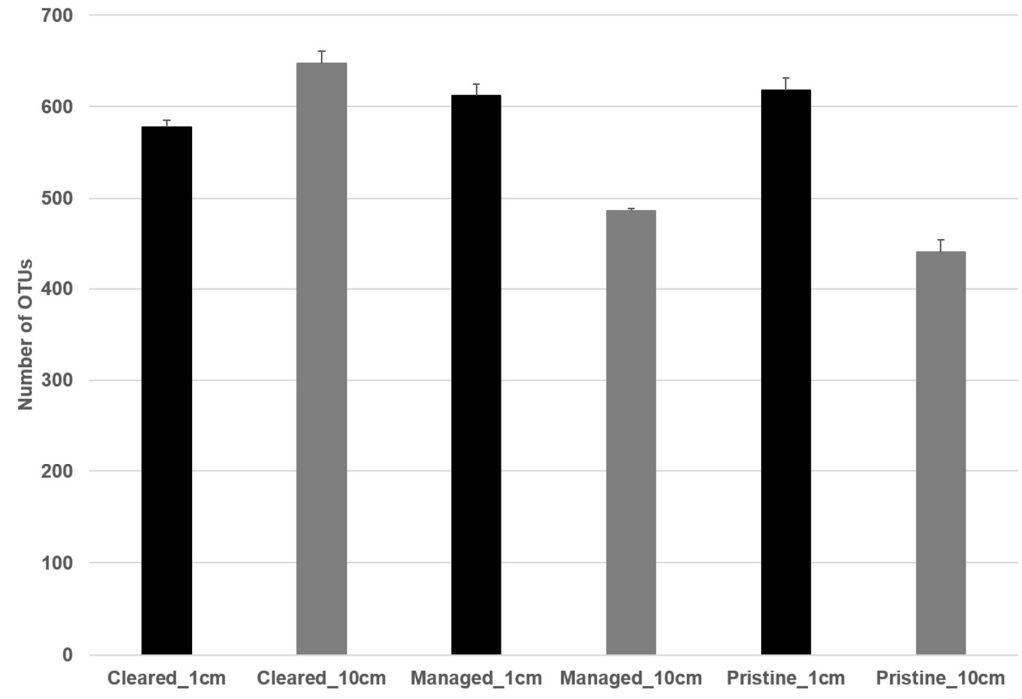

Figure 2. Soil fungi richness per land-use and depth combination (number of OTUs averaged per combination). Black bars: $1 \mathrm{~cm}$ depth; gray bars: $10 \mathrm{~cm}$ depth. 
Shannon, Simpson, Inverse Simpson, Evenness $\left(\mathrm{J}^{\prime}\right)$, Alpha and Gamma contribution to diversity (by Simpson index) index values were higher in the Cleared plot samples compared to samples from the other two landuses (Table 2). Contrastingly, the Berger index and Beta contribution to diversity (by Simpson index) were lowest in the Cleared plot samples (Table 2).

In all plots, beta diversity contribution to gamma diversity was low, though slightly higher in the Pristine_10 cm samples (Table 2). Richness and Shannon indices were lower at $1 \mathrm{~cm}$ than at $10 \mathrm{~cm}$ depth in the Cleared plot, but an inverse pattern was found in the Managed and Pristine plots (Table 2). Land-use, depth, and their interaction were found to be important predictors of richness and diversity indices (Table 2).

In total, four Phyla and one Subphylum were detected: Ascomycota, Basidiomycota, Chytridiomycota, Zygomycota, and Glomeromycotina, being the first two dominant in all treatments (63-92\% of all reads) (Figure 3). Basidiomycota represented up to $55 \%$ of all fungi detected in the Pristine and Managed plots samples, but this Phylum was less prominent in the Cleared plot samples (13-20\%). Contrarily, the abundance of Chytridiomycota was higher in the Cleared plot samples, as it accounted for $3-16 \%$ of all reads. Overall, Agaricomycetes, Dothideomycetes, and Sordariomycetes were the most abundant fungal classes in the six treatments (Figure 3). Chytridiomycetes were highly abundant in the Cleared plot but almost absent in the Managed and Pristine plots (Figure 3). Contrarily, Archaeorhizomycetes were quite abundant in soil samples obtained from the Managed and Pristine plots but were almost absent in the Cleared plot (Figure 3).

\subsection{Functional characterization of fungal communi- ties}

Of the total 1,173 OTUs, 401 OTUs (29.17\%; 23,994 reads) could be assigned to a functional fungal guild. Of these, 319 OTUs belonged to saprotrophic fungi, 40 to plant pathogens, 20 to EM fungi, nine to animal parasites, eight to AM fungi, eight to mycoparasites, two to lichenized fungi and one to biotroph fungi. Due to the high variation in functionally assigned reads per sample, reads were rarified to 1,333 reads per sample, which was the lowest number of functionally assigned reads per sample obtained (sample Pristine_1 cm.2). In general, the abundance of OTUs related to AM fungi was low (Figure 4). The relative abundance of saprotrophic fungi was higher in the Managed and Pristine plots compared to the Cleared plot (Figure 4a). The relative abundance and richness of EM fungi were highest in the Pristine plot. Although the richness of plant pathogenic fungi was similar in all land-use types (Figure 4b), the relative abundance of these fungi was higher in the Cleared plot compared to the other treatments (Figure 4a). Land-use, depth, and their interaction showed significant effects on the richness of saprotroph and plant pathogen fungi (Table 3); the relative abundance of plant pathogen fungi was significantly affected by land-use and depth, though the interaction between land-use and depth was no significant (Table 3). 


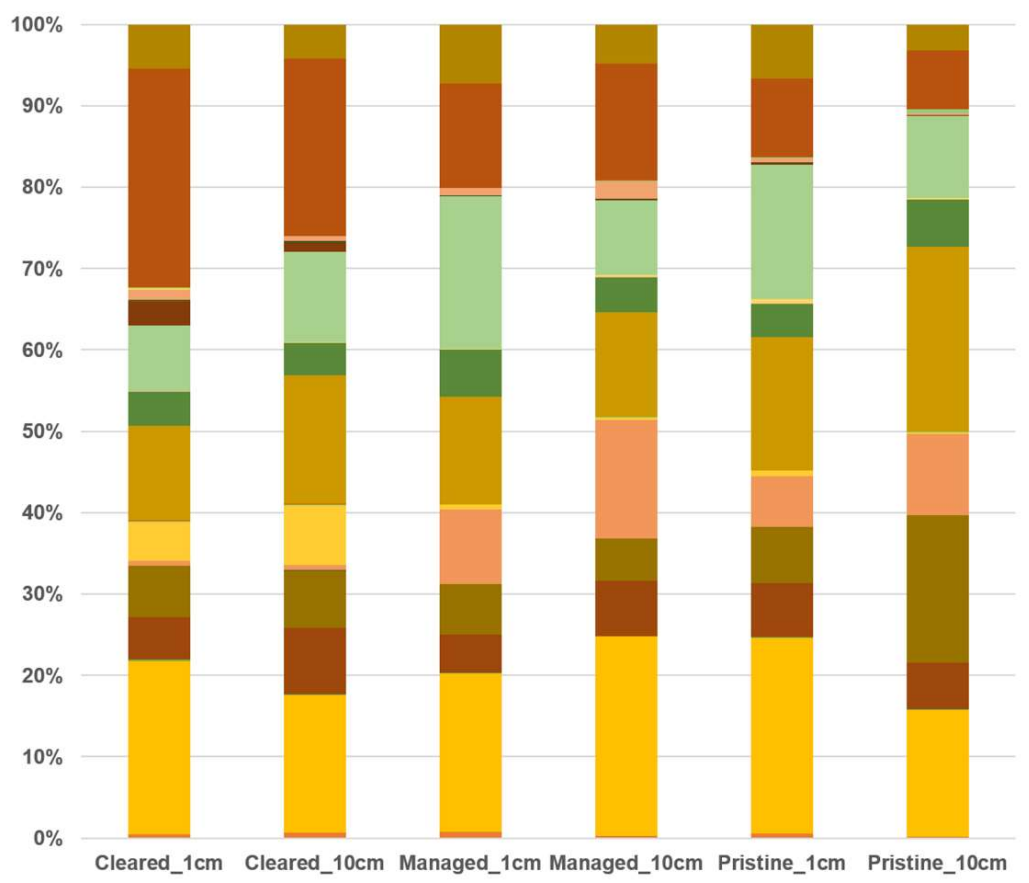

- Tremellomycetes - Sordariomycetes $n$ Saccharomycetes

ePucciniomycetes

- Pezizomycetes

- Orbiliomycetes

- Monoblepharidomycetes

- Microbotryomycetes

- Leotiomycetes

- Lecanoromycetes

Glomeromycetes

Eurotiomycetes

- Dothideomycetes

- Dacrymycetes

- Chytridiomycota

Chytridiomycetes

Archaeorhizomycetes

- Archaricostilbomycetes

- Agaricomycetes

- Zygomycota

- Basidiomycota

- Ascomycota

m Fungi
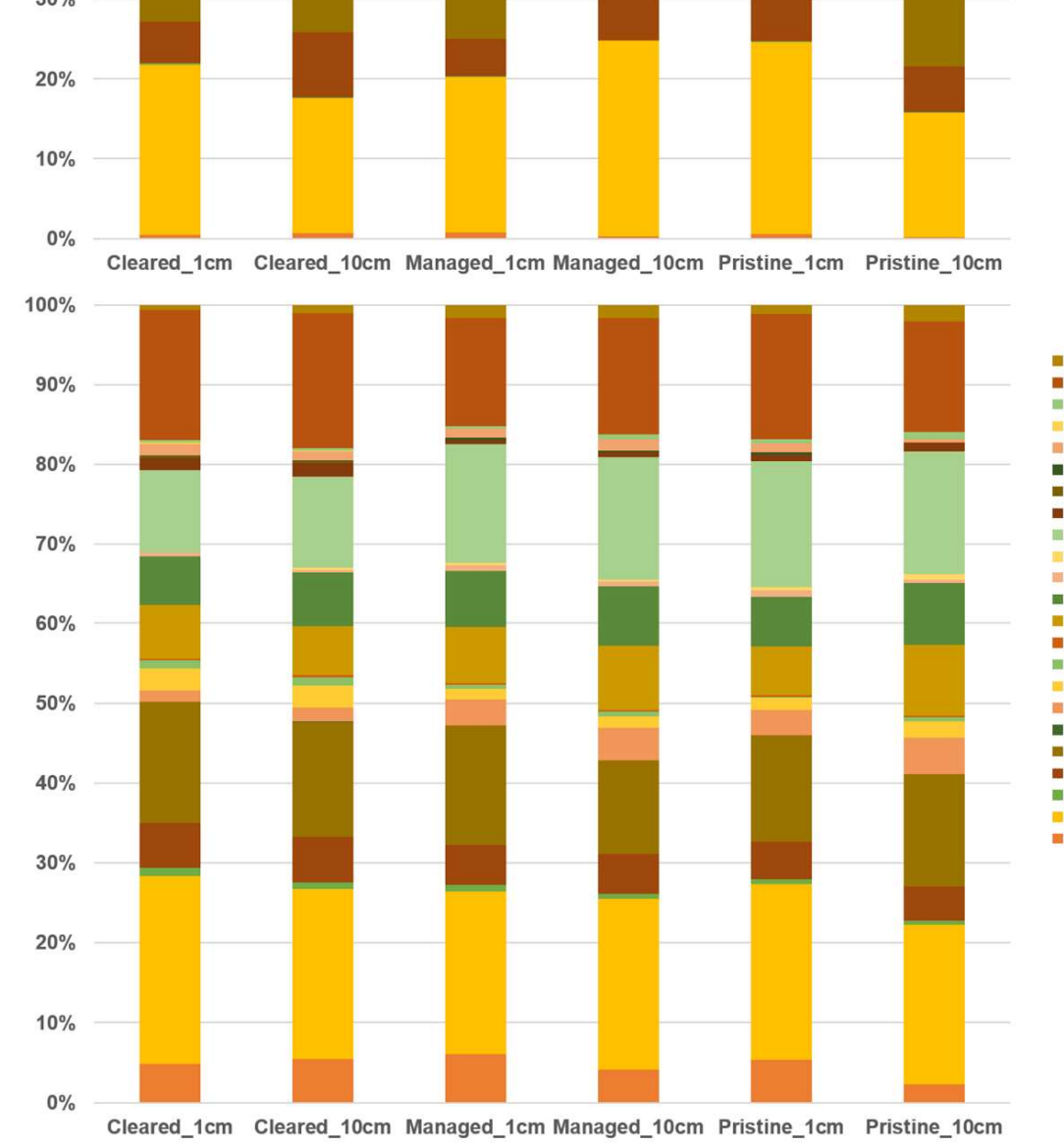

- Tremellomycetes - Sordariomycetes Saccharomycetes -Saccharomycetes
Pucciniomycetes - Pezizomycetes - Orbiliomycetes - Monoblepharidomycetes - Microbotryomycetes - Leotiomycetes Lecanoromycetes - Glomeromycetes E Eurotiomycetes Dothideomycetes Dacrymycetes Dacrymycetes
Chytridiomycota - Chytridiomycetes Archaeorhizomycetes - Agaricostilbomycetes Agaricomycetes - Zygomycota - Basidiomycota Ascomycota a Fungi

Figure 3. a. Proportional abundance of classes (or higher taxonomical level) by land-use and depth combination. b. Proportional richness (number of OTUs) by class (or higher taxonomical level) for each land-use and depth combination. 
Table 3. Linear models showing the effects of land-use, depth, and their interaction on the richness and abundance of saprotroph, ectomycorrhizal (EM) and plant pathogen fungi.

\begin{tabular}{lllllll}
\hline & \multicolumn{2}{c}{ Saprotroph } & \multicolumn{2}{c}{ EM } & \multicolumn{2}{c}{ Plant pathogen } \\
& Richness & Abundance & Richness & Abundance & Richness & Abundance \\
\hline Vegetation & $10.675^{* *}$ & $0.395^{\text {ns }}$ & $0.851^{\text {ns }}$ & $0.501^{\text {ns }}$ & $24.364^{* * *}$ & $47.344^{* * *}$ \\
Depth & $14.214^{* *}$ & $0.423^{\text {ns }}$ & $2.649^{\text {ns }}$ & $0.409^{\text {ns }}$ & $10.922^{* *}$ & $5.126^{*}$ \\
Vegetation*Depth & $9.432^{* *}$ & $0.316^{\text {ns }}$ & $1.068^{\text {ns }}$ & $0.205^{\text {ns }}$ & $3.948^{*}$ & $0.125^{\text {ns }}$ \\
& $\mathrm{r}^{2}=0.819$ & $\mathrm{r}^{2}=0.133$ & $\mathrm{r}^{2}=0.351$ & $\mathrm{r}^{2}=0.132$ & $\mathrm{r}^{2}=0.849$ & $\mathrm{r}^{2}=0.893$ \\
\hline
\end{tabular}

$\mathrm{F}^{p}, \mathrm{p}: *<0.05,{ }^{* *}<0.01, * * *<0.001, \mathrm{~ns}=$ non-significant.

For total fungi, there were almost no significant differences in alpha diversity and evenness between treatments according to the Rényi profiles. One exception was the slightly lower alpha diversity and evenness of the Pristine_10 cm treatment compared to the other treatments (Figure 3). Some differences in alpha diversity and evenness were, however, observed when the Rényi profiles were calculated for specific guilds (saprotroph, EM and plant pathogen fungi; Figure 5).

\subsection{Edaphic characteristics structuring soil fungal} communities

While depth was important for structuring soil fungal communities in the Managed and Pristine plots, fungal communities obtained from the soil samples of the Cleared plot were highly similar, independent of depth (Figure 6a). A similar result was found regarding saprotroph community composition (Figure 6b). EM and plant pathogen fungi communities were highly influenced both by land-use and depth (Figure $6 \mathrm{c}, \mathrm{d})$. Saprotroph and EM fungal communities were affected by almost the same soil variables (Figure $6 \mathrm{~b}, \mathrm{c}$ ) while plant pathogen fungal communities were structured by EC, $\mathrm{P} \_\mathrm{a}$, and K (Figure 6d). 


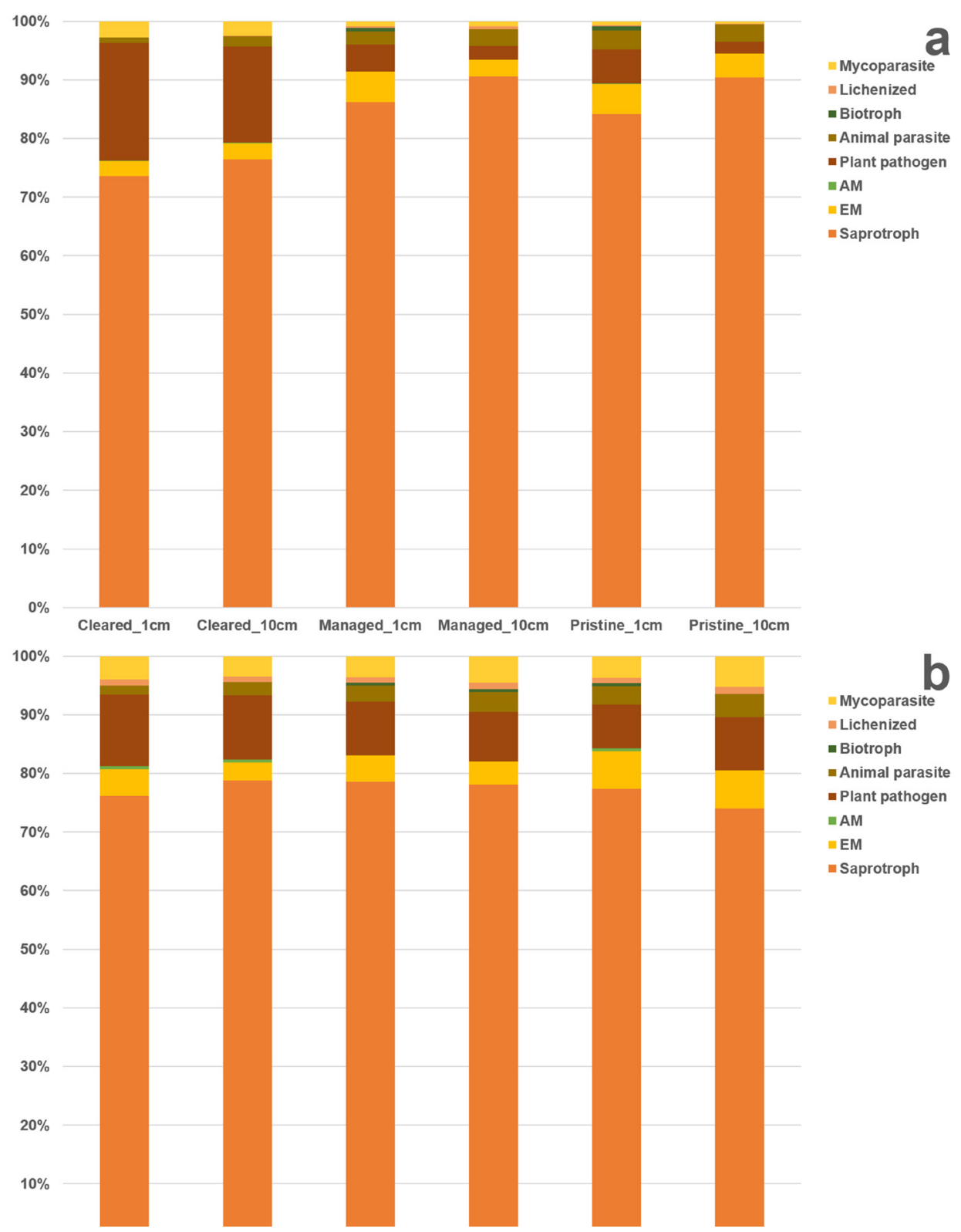

Figure 4. Fungal guild assignment for each land-use and depth combination. Reads per sample were rarified to 1,333 reads, which was the lowest number of functionally assigned reads for any given sample (belonged to sample two of the Pristine_1 cm combination). a. Proportional abundance of fungal guilds by land-use and depth combination. b. Proportional richness (number of OTUs) by fungal guild for each land-use and depth combination. 
a

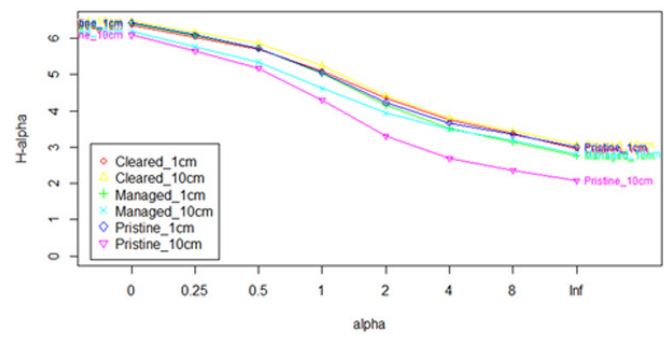

C

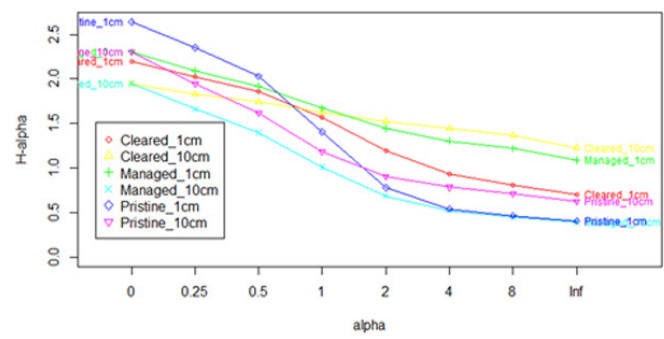

b

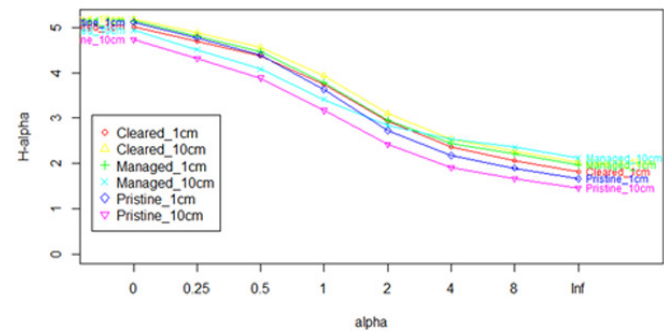

d

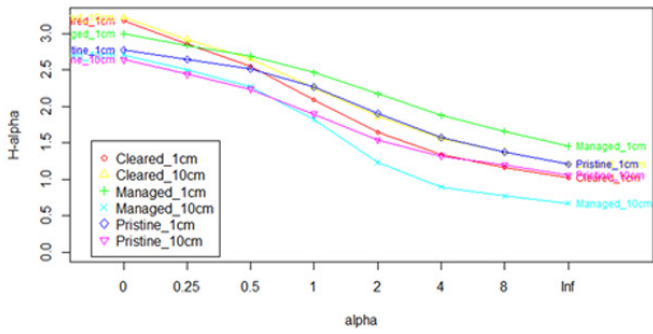

Figure 5. a. Rényi diversity profile per combination for total soil fungi. b. Rényi diversity profile per combination for saprotroph fungi. c. Rényi diversity profile per combination for ectomycorrhizal fungi. d. Rényi diversity profile per combination for plant pathogen fungi. 
a

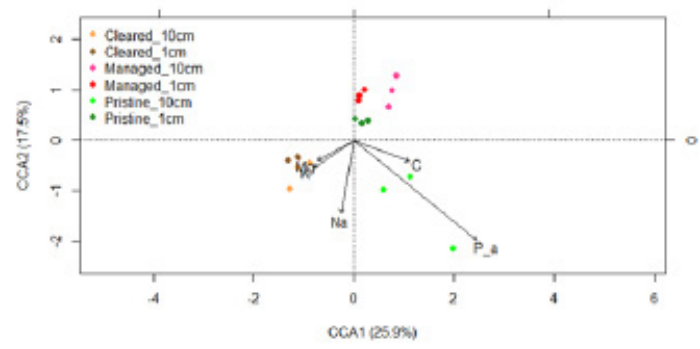

c

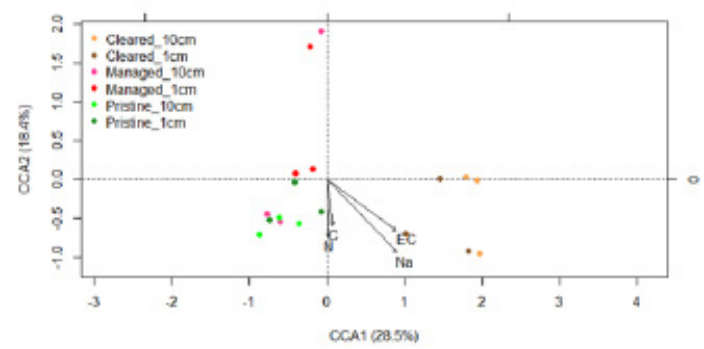

b

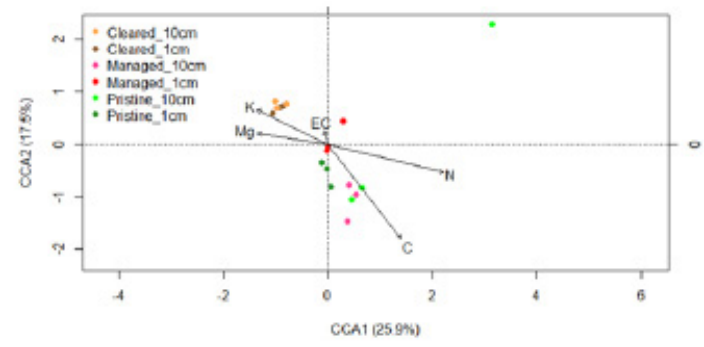

d

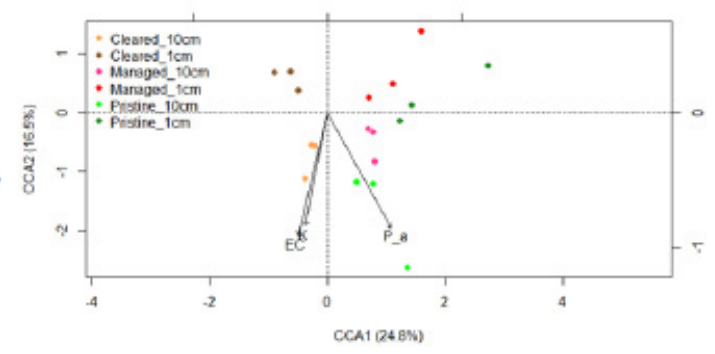

Figure 6. Canonical Correspondence Analysis (CCA) models for total soil fungi and selected guilds (ANOVA for CCA, 1,000 permutations; order of soil chemical variables selected based on backward model selection; variance explained in brackets), for the 18 samples, and for each land-use and depth combination. a. CCA for total soil fungi (model: $\sim \mathrm{C}+\mathrm{P} \_\mathrm{a}+\mathrm{K}+\mathrm{Mg}+\mathrm{Na}$; F: 1.757, significance: 0.001). b. CCA for saprotroph fungi (model: $\sim \mathrm{EC}+\mathrm{C}$ $+\mathrm{N}+\mathrm{K}+\mathrm{Mg}$; F: 1.931, significance: 0.001). c. CCA for ectomycorrhizal fungi (model: $\sim \mathrm{EC}+\mathrm{C}+\mathrm{N}+\mathrm{Na}$; F: 2.382, significance: 0.001 ). d. CCA for plant pathogen fungi (model: $\sim \mathrm{EC}+\mathrm{P} \_\mathrm{a}+\mathrm{K} ; \mathrm{F}: 2.139$, significance: 0.004).

\section{Discussion}

Functional compensation strategies are related to the concept of 'nestedness' (James et al., 2012), in which more specialist species result from ecological succession. Here we found evidence for this as the richness and relative abundance of saprotrophic and EM fungi were highest in the Pristine plot which represents a late stage of ecological succession (Oyarzún et al., 2007; Kitzberger et al., 2016). The opposite pattern was found in the plot representing an initial successional state (clear-cut forest), were richness and relative abundance of saprotrophic and EM fungi were lowest. While animal and plant communities have been shown to have a high degree of nestedness (James et al., 2012), this concept has rarely been applied to soil microbial communities (Castillo et al., 2016). Nestedness, however, should not be mistaken for community composition or structure; the latter refers to the abundance and type of species present in a community. For example, here the Pristine plot had the highest nestedness (higher relative abundance and richness of specialist saprotrophic and EM fungi), and it also had the most variable community composition. Specialist saprotrophic and EM fungi are required towards the advance of the ecological succession. The fungal guilds found in this study which are not directly related to nutrient cycling, as plant pathogen 
fungi were less diverse in the Pristine plot and more abundant in the Cleared plot. This result reinforced our general expectation of higher diversity of nutrient cycling-related guilds on pristine ecosystems (Godoy et al., 2009; Medina et al., 2015; Kitzberger et al., 2016). Overall, the forest plot had poor edaphic nutrient status compared to other world forests, which would likely foster specialization of nutrient-cycling related fungi (Godoy et al., 2009; James et al., 2012).

The proximity of the plots to one another may explain the low level of endemism (8.6\%), defined here as OTUs present in only one of the six treatments. It is important to note that $30.8 \%$ of the OTUs were shared between at least two treatments (either land-use or soil depth), meaning that, almost a third of the OTUs were found at both depths in one of the three types of plots (Cleared, Managed, Pristine). This result gives further support for the concept of nestedness -generalist fungi would predominate before being replaced by specialist fungi during succession (James et al., 2012). Although it can be expected that fungal communities at different soil depths are different in terms of community composition and function (Valenzuela et al., 2001), almost a third of the OTUs were shared at both depths.

Regarding the abiotic soil properties (soil chemistry), the most striking result was that in the Pristine plot, the differences between both depths $(1 \mathrm{~cm}$ and $10 \mathrm{~cm}$ ) were less pronounced compared to the other two treatments. This result contradicts the expectation that a major anthropogenic intervention would have an 'homogenization effect' on soil abiotic properties (Valenzuela et al., 2001). This being said, the small differences in composition of the soil fungal community of the Cleared plot, does reflect an homogenization effect. A further development of this results could be to search the mechanisms that cause an homogenization of soil fungal communities at both depths with increasing disturbance, but no homogenization on soil chemistry.
Land-use, depth, and their interaction clearly affected saprotroph fungal richness and abundance as well as plant pathogen fungal richness, but EM richness and abundance were not affected. This could be in part explained by 'functional compensation.' Specifically, clear-cut vegetation, despite having greater phylogenetic soil fungal richness, also had a higher relative richness of plant pathogen fungi. The abundance of plant pathogen fungi increased with increasing intensity of anthropogenic intervention; it is possible that this is due to litter removal and the simplification of the vegetation structure which would facilitate the dispersion of plant pathogens. Furthermore, the Pristine and Managed plots had higher mycorrhizal fungal abundance. This could be explained as an indirect mechanism, as mycorrhizas are well known to protect against pathogens. This inverse relationship between plant pathogen fungi (higher abundance in more intervened systems) and both saprotroph and EM fungi (higher abundance in less intervened systems) was reinforced by the CCA results. In the CCA the edaphic characteristics structuring total soil fungi as well as saprotrophic and EM fungi were somewhat similar while those structuring plant pathogen fungi differed.

\section{Conclusions}

Although phylogenetic fungal richness was found to be higher in the Cleared plot, this plot had the lowest proportion of saprotrophic fungi, the highest proportion of plant pathogen fungi, and almost no ectomycorrhizal fungi. Meanwhile, the Pristine plot samples had the lowest phylogenetic fungal richness and a high abundance of saprotroph fungi, but the abundances of plant pathogen fungi and ectomycorrhizal fungi were low. These results are in accordance with our hypothesis that pristine ecosystems would have a higher proportion of fungi that drive nutrient-cycling. From this, it can be concluded that the soil fungal 
community has functional compensation strategies in response to disturbance. Specifically, the lower phylogenetic diversity found in the Pristine plot could be compensated by a higher diversity of fungal guilds directly involved in nutrient-cycling. Thus, it is important to measure functional diversity, rather than just phylogenetic richness, when evaluating the state of an ecosystem.

\section{In memorian of Eduardo Valenzuela:}

"The authors are deeply saddened by the lost of our colleague, professor and friend, Prof. Dr. Eduardo Valenzuela, co-author of this study. His inmense work and love for Chilean mycology will live in our memory and will surpass generations to come. Thank you, Eduardo."

\section{Acknowledgements}

The authors thank Emily Giles for her help and critical comments on this manuscript. Special thanks to Mónica Barrientos and Juan Fuentealba for laboratory help and to the National Forest Corporation of Chile (CONAF), and the park ranger Nicolás Pacheco. This work was supported by The National Commission for Scientific and Technological Research of Chile (National Doctorate Scholarship No. 21150047 to C.M.), by The National Fund for Scientific and Technological Development (Project No. 1141060 to C.M., R.B. and J.B.), and by The German Research Foundation - Priority Programs (Program 1803-EarthShape project to R.B. and J.B.).

\section{References}

Aguilera, P., Marín, C., Oehl, F., Godoy, R., Borie, F., Cornejo, P.E. 2017. Selection of aluminum tolerant cereal genotypes strongly influences the arbuscular mycorrhizal fungal communities in an acidic Andosol. Agric. Ecosyst. Environ. 246, 86-93.

Bååth, E., Frostegård, Å., Pennanen, T., Fritze, H. 1995. Microbial community structure and $\mathrm{pH}$ response in relation to soil organic matter quality in wood-ash fertilized, clear-cut or burned coniferous forest soils. Soil Biol. Biochem. 27, 229-240.

Bueno, C.G., Marín, C., Silva-Flores, P., Aguilera, P., Godoy, R. 2017. Think globally, research locally: contrasting patterns of mycorrhizal symbiosis in South America. New Phytol. 215, 1306-1309.

Caporaso, J.G., Kuczynski, J., Stombaugh, J., Bittinger, K., Bushman, F.D., Costello, E.K., Huttley, G.A. 2010. QIIME allows analysis of highthroughput community sequencing data. Nature Methods. 7, 335-336.

Castillo, C.G., Oehl, F., Sieverding, E. 2016. Arbuscular mycorrhizal fungal diversity in wheat agroecosystems in Southern Chile and effects of seed treatment with natural products. J. Soil Sci. Plant Nutr. 16(4), 967-978.

Cornejo, P., Meier, S., García, S., Ferrol, N., Durán, P., Borie, F., Seguel, A. 2017. Contribution of inoculation with arbuscular mycorrhizal fungi to the bioremediation of a copper contaminated soil using Oenothera picensis. J. Soil Sci. Plant Nutr. 17(1), 14-21.

Gardes, M., Bruns, T.D. 1996. Community structure of ectomycorrhizal fungi in a Pinus muricata forest: above-and below-ground views. Can. J. Bot. $74,1572-1583$. 
Garrido, E., Matus, F. 2012. Are organo-mineral complexes and allophane content determinant factors for the carbon level in Chilean volcanic soils? Catena. 92, 106-112.

Godoy, R., Romero, R., Carrillo, R. 1994. Estatus micotrófico de la flora vascular en bosques de coníferas nativas. Rev. Chil. Hist. Nat. 67, 209-220.

Godoy, R., Paulino, L., Valenzuela, E., Oyarzún, C., Huygens, D., Boeckx, P. 2009. Temperate ecosystems of Chile: characteristic biogeochemical cycles and disturbance regimes. In: N. Verhoest, P. Boeckx, C. Oyarzún, R. Godoy (eds). Ecological advances on Chilean temperate rainforests. Academia Press, Ghent, pp: 31-40.

Hagerman, S.M., Jones, M.D., Bradfield, G.E., Gillespie, M., Durall, D.M. 1999. Effects of clear-cut logging on the diversity and persistence of ectomycorrhizae at a subalpine forest. Can. J. Forest Res. 29, 124-134.

Holden, S.R., Treseder, K.K. 2014. A meta-analysis of soil microbial biomass responses to forest disturbances. Front. Microbiol. 4, 1-17.

James, A., Pitchford, J.W., Plank, M.J. 2012. Disentangling nestedness from models of ecological complexity. Nature. 487, 227-230.

Kindt, R., Coe, R. 2005. Tree diversity analysis: a manual and software for common statistical methods for ecological and biodiversity studies. World Agroforestry Centre, Nairobi, $196 \mathrm{p}$.

Kitzberger, T., Perry, G.L.W., Paritsis, J., Gowda, J.H., Tepley, A.J., Holz, A., Veblen, T.T. 2016. Fire-vegetation feedbacks and alternative states: common mechanisms of temperate forest vulnerability to fire in southern South America and New Zealand. New Zeal. J. Bot. 54, 247-272.

Lauber, C.L., Strickland, M.S., Bradford, M.A., Fierer, N. 2008. The influence of soil properties on the structure of bacterial and fungal communities across land-use types. Soil Biol. Biochem. 40, 2407-2415.

Marín, C., Aguilera, P., Cornejo, P., Godoy, R., Oehl, F., Palfner, G., Boy, J. 2016. Arbuscular mycorrhizal assemblages along contrasting Andean forests of southern Chile. J. Soil Sci. Plant Nutr. 16(4), 916-929.

Matus, F. 2003. Enrichment of carbon in particles-size separates of soils with different land-use managements. J. Soil Sci. Plant Nutr. 3, 29-36.

Medina, J., Meier, S., Rubio, R., Curaqueo, G., Borie, F., Aguilera, P., Oehl, F., Cornejo, P. 2015. Arbuscular mycorrhizal status of pioneer plants from the mouth of lake Budi, Araucanía Region, Chile. J. Soil Sci. Plant Nutr. 15, 142-152.

Mueller, R.C., Rodrigues, J.L.M., Nüsslein, K., Bohannan, B.J.M. 2016. Land use change in the Amazon rain forest favours generalist fungi. Funct. Ecol. 30, 1845-1853.

Oksanen, J., Blanchet, F.G., Kindt, R., Legendre, P., Minchin, P.R., O'Hara, R.B., Simpson, G.L., Solymos, P., Stevens, M.H.H., Wagner, H. 2015. Vegan: Community Ecology Package. R package version 2.3-1. http://CRAN.R-project.org/ package $=$ vegan

Oyarzún, C.E., Godoy R., De Schrijver A., Staelens J., Lust N. 2004. Water chemistry and nutrient budgets in an undisturbed evergreen rainforest of southern Chile. Biogeochemistry. 71, 107-123.

Oyarzún, C., Aracena, C., Rutherford, P., Godoy. R., De Schrijver, A. 2007. Effect of land use conversion from native forests to exotic plantations on streamwater quality in southern Chile. Water Air Soil Pol. 179, 341-350.

Pandey, R.V., Nolte, V., Schlötterer, C. 2010. CANGS: a user-friendly utility for processing and analyzing 454 GS-FLX data in biodiversity studies. BMC Res. Notes. 3, 3. 
R Development Core Team. 2016. R: A Language and Environment for Statistical Computing. The R Foundation for Statistical Computing, Vienna. Available online at http://www.R-project.org/

Schloss, P.D., Westcott, S.L., Ryabin, T., Hall, J.R., Hartmann, M., Hollister, E.B., Sahl, J.W. 2009. Introducing mothur: open-source, platform-independent, community-supported software for describing and comparing microbial communities. Appl. Environ. Microb. 75, 7537-7541.

Spurgeon, D.J., Keith, A.M., Schmidt, O., Lammertsma, D.R., Faber, J.H. 2013. Land-use and landmanagement change: relationships with earthworm and fungi communities and soil structural properties. BMC Ecology, 13, 1.

Tedersoo, L., Bahram, M., Põlme, S., Kõljalg, U., Yorou, N.S., Wijesundera, R., Abarenkov, K. 2014. Global diversity and geography of soil fungi. Science. 346, 1256688.

Töwe, S., Wallisch, S., Bannert, A., Fischer, D., Hai, B., Haesler, F., Schloter, M. 2011. Improved protocol for the simultaneous extraction and columnbased separation of DNA and RNA from different soils. J. Microbiol. Meth. 84, 406-412.

Valenzuela, E., Leiva, S. Godoy, R. 2001. Variación estacional y potencial enzimático de microhongos asociados con la descomposición de hojarasca de Nothofagus pumilio. Rev. Chil. Hist. Nat. 74, 737-749. van Der Heijden, M.G., Bardgett, R.D., van Straalen, N.M. 2008. The unseen majority: soil microbes as drivers of plant diversity and productivity in terrestrial ecosystems. Ecol. Lett. 11, 296-310.

Walkley, A., Black, I.A. 1934. An examination of Degtjareff method for determining soil organic matter and a proposed modification of the chromic acid titration method. Soil Sci. 37, 29-37.

White, T.J., Bruns, T., Lee, S. J. W.T., Taylor, J.W. 1990. Amplification and direct sequencing of fungal ribosomal RNA genes for phylogenetics. PCR Protocols: a Guide to Methods and Applications. $18,315-322$.

Wubet, T., Christ, S., Schöning, I., Boch, S., Gawlich, M., Schnabel, B., Buscot, F. 2012. Differences in soil fungal communities between European beech (Fagus sylvatica L.) dominated forests are related to soil and understory vegetation. PloS One. 7, e47500.

Zagal, E., Sadzawka, A. 2007. Protocolo de métodos de análisis para suelos y lodos. Servicio Agrícola y Ganadero, Santiago, 103 p.

Zhao, J., Wang, X., Shao, Y., Xu, G., Fu, S. 2011. Effects of vegetation removal on soil properties and decomposer organisms. Soil Biol. Biochem. 43, 954-960. 